\title{
Polydrug Use: Why is it so Dangerous?
}

\section{Fernández-Calderón Fermín*}

Department of Clinical, Social and Experimental Psychology, University of Huelva, Spain

Nowadays, polydrug use is predominant among drug users [1], being especially associated with some specific recreational contexts such as clubs, festivals or raves [2].

Polydrug use can be defined as consecutive or concomitant use of different drugs [3], and it is carried out with different purposes. On the one hand, some people try to achieve new effects or experiences which cannot be provided for each substance separately. Furthermore, the mixing of substances is carried out to reduce the unwanted effects or to enhance the desired ones [4-6].

Polydrug use can result in potentially negative consequences on people's health. It is possible that effects boost themselves, interact or even new ones emerge, complicating the intervention on acute intoxication episodes [7]. For instance, there is agreement about alcohol consumption increases the blood levels of cocaine around $30 \%$. Besides, it contributes to the synthesis of cocaethylene, a psychoactive metabolite of cocaine with a major duration in blood [3]. Nonetheless, the certainties about the effects of polydrug use and their consequences on health are in most cases unknown. It is common that when alerting on the risk associated to polydrug use, to refer to the impossibility of predict the pharmacological resulting effects. Therefore, polydrug use consequences are both unknown and feared.

The design and implementation of effective strategies for prevention and risk/harm reduction should necessarily emerge from two sources of knowledge. On the one hand, it is necessarily to identify polydrug use patterns, particularly: more used substances, substance mixed, administration order, quantity, etc... Furthermore, it is necessary further progress on the knowledge of different effects related to interactions among different polydrug use patterns. An in-depth knowledge of different patterns of polydrug use and related effects will provide to social and policy makers with better tools to avoid negative consequences on people's health.

Despite of recent years numerous investigations about polydrug use has been conducted, still today remains a research need and priority. This is reflected, for example, in the strategy/work program of the European Monitoring Centre for Drugs and Drug Addiction [1]. Keeping this in mind, the Open Access publication model is appropriated to spread this kind of knowledge. We must keep adding answers to this question: why is polydrug use so dangerous? As a member of the editorial board, I would like to encourage researchers to carry out investigations on this important topic and send their articles to the Journal of Socialomics.

\section{References}

1. European Monitoring Centre for Drugs and Drug Addiction: EMCDDA Strategy and Work Programme 2013-2015. Publications Office of the European Union, Luxembourg. Retrieved November 06, 2012.

2. Fernández-Calderón $F$, Lozano $O M$, Vidal C, Gutiérrez J, Vergara E, et al (2011) Polysubstance Use Patterns in Underground Rave Attenders: A Cluster Analysis. J Drug Educ 41: 183-202.

3. European Monitoring Centre for Drugs and Drug Addiction: Polydrug use: Pattens and responses. Publications Office of the European Union, Luxembourg.

4. Hunt G, Evans K, Moloney M, Bailey N (2009) Combining different substances in the dance scene: enhancing pleasure, managing risk and timing effects. $J$ Drug Issues 39: 495-522.

5. Lankenau SE, Clatts MC (2005) Patterns of Polydrug Use among Ketamine Injectors in New York City. Subs Use Misuse 40: 1381-1397.

6. Klein H, Elifson KW, Sterk CE (2009) Young adult Ecstasy user's enhancement of the effects of their ecstasy use. J Psychoactive Drugs 41: 113-120.

7. Ricaurte GA, McCann UD (2005) Recognition and management of complications of new recreational drug use. The Lancet 365: 2137-145.
*Corresponding author: Fernández-Calderón Fermín, Department of Clinical, Social and Experimental Psychology, University of Huelva, Spain, E-mail: fermin.fernandez@juntadeandalucia.es

Received November 13, 2012; Accepted November 19, 2012; Published November 26, 2012

Citation: Fermín FC (2013) Polydrug Use: Why is it so Dangerous? J Socialomics 2: e112. doi:10.4172/2167-0358.1000e112

Copyright: (C) 2013 Fermín FC. This is an open-access article distributed unde the terms of the Creative Commons Attribution License, which permits unrestricted use, distribution, and reproduction in any medium, provided the original author and source are credited. 